\title{
Twelfth rib syndrome- an often missed differential diagnosis of hypogastric \& lumbar pain: case series
}

\author{
Sangeeta Arya ${ }^{1}$, Anil Kumar Verma ${ }^{2}$, Bikram Kumar Gupta ${ }^{2}$, \\ Mohd. Hifzur ${ }^{3}$, Sachidanand Gupta ${ }^{4}$, Neetu Singh ${ }^{1}$
}

\author{
${ }^{1}$ Department of Obstetrics \& Gynecology, G.S.V.M. Medical College, Kanpur - 208002, Uttar Pradesh, India \\ ${ }^{2}$ Department of Anaesthesiology \& Critical care, G.S.V.M. Medical College, Kanpur - 208002, Uttar Pradesh, India \\ ${ }^{3}$ Department of Physiology, G.S.V.M. Medical College, Kanpur - 208002, Uttar Pradesh, India \\ ${ }^{4}$ Department of Anaesthesiology, Rama Medical College, Kanpur - 209217, Uttar Pradesh, India
}

Received: 01 January 2014

Accepted: 02 February 2014

\section{*Correspondence:}

Dr. Bikram Kumar Gupta,

E-mail: bikramgupta03@gmail.com

(C) 2014 Arya S et al. This is an open-access article distributed under the terms of the Creative Commons Attribution Non-Commercial License, which permits unrestricted non-commercial use, distribution, and reproduction in any medium, provided the original work is properly cited.

\begin{abstract}
The twelfth rib syndrome appears to be a fairly common and underdiagnosed chronic pain syndrome. The diagnosis of this syndrome is clinical, requires exclusion of specific etiologies, and should only be made when the patient's symptoms can be exactly reproduced by manipulation of the affected rib. Patients with this syndrome can be over investigated and have even undergone surgical procedures when this diagnosis has been overlooked. We present here a case series of 27 women of twelfth rib syndrome over a period span of 18 months, many of whom had come to us after having prolonged and ineffective treatment for lumbar or hypogastric pain. Such patients were successfully managed with infiltration of local anaesthetics and steroid.
\end{abstract}

Keywords: Twelfth rib syndrome, Lower abdominal pain, Conservative management, Local anaesthetics

\section{INTRODUCTION}

Today in the world of investigations we have nearly forgotten the clinical diagnosis and presentation of some diseases and sometimes go for unnecessary investigations. The scenario with twelfth rib syndrome also called as Intercostal neuralgia is the same. This is a common and under diagnosed chronic or acute painful disorder causing constant dull aching or sharp stabbing pain in the lumbar and suprapubic area for weeks or years. The incidence of twelfth rib syndrome is more in women than men in ratio $3: 1 .^{1}$ It can be easily diagnosed clinically by manipulation of the tip of the twelfth rib and its cartilage, exactly reproducing the same pain in the lumbar and suprapubic area which woman complaint of. ${ }^{2}$ We present here a case series of 27 women over a period span of 18 months, many of whom had come to us after having prolonged and ineffective treatment for lumbar or hypogastric pain.

\section{CASE REPORT}

Our first case worth mentioning as at first we also missed the diagnosis and went for unnecessary investigations. A 24 year old primipara came to OPD with complaint of off $\&$ on severe pain around the incision site (Pfannenstiel incision), more on left side since her $7^{\text {th }}$ post-operative period of caesarean section (done three months back in a private hospital). Pain was aggravated by changing position, side bending and mainly during picking up her baby from bed. For this she was advised painkiller (ibuprofen + paracetamol) by her treating obstetrician. She was partially relieved for 7-8 days but after that pain hampered her day today life and was unable to hold her baby for breast feeding specially on the left side. There 
was no history of trauma in the recent past. After consulting two physicians and a gastroenterologist she was referred to us. On examination her stitch line had healed with primary intention. There were no signs of inflammation and on palpation there was severe tenderness in the suprapubic area extending into the left lumbar region. On per speculum and per vaginal examination no abnormality was found. After thorough history and clinical examination we were not sure of diagnosis, and so we advised her for whole abdomen ultrasound and prescribed analgesics - ibuprofen + paracetamol and chymotrypsin. After 5 days she came back and told that her pain was relieved only partially with drug but recurred as soon as the drug effect weaned off. Her ultrasound report was also within normal limits. Still getting not sure of any pathology we referred her to Psychiatry OPD where antidepressants with opioids were advised for seven days by which also she got only mild relief according to VAS score. Now she was referred to pain clinic in our college. There she was examined and was diagnosed to have twelfth rib syndrome. She was given local injection of local anesthetic ( $2 \mathrm{ml}$ of $1 \%$ xylocaine) for diagnostic purpose - the pain relief was instant and nearly $100 \%$ according to VAS system and later steroid injection was given by pain clinician as a long-lasting measure.

In this case series women belonged to 20-50 years of age with maximum $44.4 \%$ belonging to $40-50$ age groups (Table 1). Pain was usually aggravated by side bending and household work like sweeping or wiping the floor and was relieved on forward bending. Most of the women suffered with this pain for last 3-5 years. All women had minimum one visit to a physician, $70 \%$ had visits to urosurgeons and $56 \%$ had visits to a gastroenterologist. $100 \%$ women had gone through USG whole abdomen (one woman carried 13 ultrasound reports with her, done over a 3 year period), 36\% cases had gone through CT scan. Colposcopy with cervical biopsy was done in $64 \%$ women and $18.5 \%$ of these women had gone through hysterectomy for the pain but in vain because symptoms still persisted after surgery (Table 1). Treatment for pelvic inflammatory disease was given to $96 \%$ cases. Several of these patients had taken antibiotic course three to four times but still were not relieved. One woman had associated sacroilitis with knee joint pain. One woman despite our reassurance and pain relief by diagnostic local anesthetic block she opted for hysterectomy as advised by other gynecologist in a private hospital. After two months of hysterectomy, she again came back with aggravation of previous pain. This time local anesthetic (LA) with steroid was infiltrated at the inflamed twelfth rib point and had significant pain relief according to VAS score.

\section{Treatment}

Tender point of twelfth rib was localized. While taking all aseptic precautions, $2 \mathrm{ml}$ of $1 \%$ plain inj. lignocaine infiltration was done in a minor OT. This was diagnostic in all and therapeutic in some. After it women were prescribed oral aceclofenac with serratiopeptidase in BD dose with cap. Pantoprazole 40mg OD and asked to come for follow up after one week. Pain assessment was done and if VAS scoring found $>4$, Injection with inj. lignocaine $1.0 \% 1 \mathrm{ml}+1.0 \mathrm{ml}$ of inj. kenacort was given along with analgesic-aceclofenac with serratiopeptidase in BD dose with cap. Pantoprazole $40 \mathrm{mg}$ OD for 5 days. Again women were asked for follow up after one week. Pain assessment was done and if VAS scoring found $>4$, Injection with inj. lignocaine $1.0 \% 1 \mathrm{ml}+1.0 \mathrm{ml}$ of inj. kenacort was given along with analgesic-aceclofenac with serratiopeptidase in BD dose with cap. Pantoprazole $40 \mathrm{mg}$ OD for 5 days. Again women were asked for follow up after one week.

Table 1: Showing demographic and clinical findings of all patients.

\begin{tabular}{|lll|}
\hline Age group & $\begin{array}{l}\text { Number of } \\
\text { patients }\end{array}$ & $\begin{array}{l}\text { Total } \\
\text { \%age }\end{array}$ \\
\hline $20-30$ yrs & 05 & 18.5 \\
\hline $30-40$ yrs & 10 & 37.0 \\
\hline $40-50$ yrs & 12 & 44.4 \\
\hline Period of pain & & \\
\hline$>5$ yrs & 06 & 22.2 \\
\hline $3-5$ yrs & 12 & 44.4 \\
\hline 3 yrs-3 mths & 07 & 25.9 \\
\hline <3 mths & 02 & 07.4 \\
\hline Side of pain & & \\
\hline Left side & 15 & 55.5 \\
\hline Right side & 11 & 40.7 \\
\hline Bilateral & 01 & 03.7 \\
\hline Aggravated by & & \\
\hline Side bending & 27 & 100 \\
\hline Sitting \& straining & 19 & 70.3 \\
\hline $\begin{array}{l}\text { While sweeping or } \\
\text { wiping floor }\end{array}$ & 19 & 70.3 \\
\hline Total No. of visits & & \\
\hline Physician & 27 & 100 \\
\hline Gastroenterologist & 19 & 70.3 \\
\hline Urologist & 21 & 77.7 \\
\hline Gynecologist & 27 & 100 \\
\hline Psychiatrist & 09 & 33.3 \\
\hline Investigations done & & \\
\hline USG abdomen & 27 & 100 \\
\hline X-ray abdomen & 17 & 62.9 \\
\hline CT/MRI & 02 & 07.4 \\
\hline Colposcopy & 11 & 40.7 \\
\hline Procedures done & & 48.1 \\
\hline Cervical biopsy & 13 & 18.5 \\
\hline Hysterectomy & 05 & 44.4 \\
\hline $\begin{array}{l}\text { Diagnostic } \\
\text { laparoscopy }\end{array}$ & 12 & \\
\hline & & \\
\hline
\end{tabular}




\section{DISCUSSION}

Pain is an unpleasant sensory experience associated with actual or potential damage to the concerned tissue causing emotional burden to the concerned and sometimes even affecting day today activity. Pain is the leading factor which brings the patient to a doctor in many conditions. Referred pain from the conditions related to ribs and intercostal nerves are not infrequently found in gynecology OPD. The first seven ribs are firmly attached to the sternum by sternocostal joints. The $8^{\text {th }}, 9^{\text {th }}$ and $10^{\text {th }}$ ribs are attached by weak interchondral joints. Sudden shearing stress on these cause a rib to slip behind the rib above it causing thoracic and upper abdominal pain and which is called as slipping rib syndrome or Teitze's syndrome. ${ }^{4}$ This can be simply clinically diagnosed by hooking maneuver in which fingers are hooked under the rib cage and tenderness is elicited over the costal margin, with referred pain in thoracic and upper abdominal area. The cause of this painful condition is not exactly known. The other causes of lumbar pain and suprapubic region like urinary calculi, pyelonephritis, and pelvic causes should also be ruled out. ${ }^{5}$ In our study women with this kind of pain were referred to physicians, gastroenterologist or urologist unnecessarily as this can be easily diagnosed by a simple clinical test and avoiding extensive investigations.

For pain relief, infiltration with local anesthetic around the concerned nerve area stops nerve transmission and allows the nerve transmission system to reset itself. Infiltration in the scar tissue also releases the entrapped nerve if any and hence releases pain. ${ }^{6}$ These injections produce noticeable pain relief in many but unfortunately not always and hence women in some studies had to go through rib resection also. ${ }^{7}$ In our case series no woman had to go under rib resection till now. Side effects of LA and steroid include numbness or tingling in the concerned area with discomfort for few days until the steroid starts working. Steroid injection works by decreasing local inflammation causing long term pain relief. Usually one injection of steroid is sufficient for pain relief but some women need repetition of injections after 2-3 weeks. Initially cortisone causes flare up of inflammation and pain may be more than the woman presented with initially but in 2-3 days the pain subsides by itself. During injection meticulous sterilization should be maintained to prevent infection.

\section{Funding: No funding sources \\ Conflict of interest: None declared \\ Ethical approval: Not required}

\section{REFERENCES}

1. Cranfield KA, Buist RJ, Nandi PR, Baranowski AP. The twelfth rib syndrome. Journal of Pain and Symptom Management. 1997;13:172-5.

2. Spence EK, Rosato EF. The slipping rib syndrome. Arch Surg. 1983;118:1330-2.

3. Gillian A. Hawker, Samra Mian, Tetyana Kendzerska, Melissa French. Measures of adult pain. Arthritis Care \& Research. 2011;63:240-52.

4. Heinz GJ, Zavala DC. Slipping rib syndrome. Diagnosis using the hooking maneuvers. JAMA. 1977;237:794-5.

5. Cyriax EF. On various conditions that may simulate the referred pains of visceral disease, and a consideration of these from the point of view of cause and effect. Practitioner. 1919;102:314-9.

6. Scott EM, Scott BB. Painful rib syndrome. Gut. 1993;34:1006-8.

7. Machin DG, Shennan JM. Twelfth rib syndrome: a differential diagnosis of loin pain. Br Med J (Clin Res Ed). 1983;287:586.

DOI: $10.5455 / 2320-1770 . i j r \operatorname{cog} 20140357$

Cite this article as: Arya S, Verma AK, Gupta BK, Hifzur M, Gupta S, Singh N. Twelfth rib syndromean often missed differential diagnosis of hypogastric \& lumbar pain: case series. Int J Reprod Contracept Obstet Gynecol 2014;3:263-5. 